\title{
Effect of single lung transplantation on pulmonary hypertension in patients with end stage fibrosing lung disease
}

\author{
J C Doig, P A Corris, C J Hilton, J H Dark, R S Bexton
}

\begin{abstract}
Objective-To investigate the effect of successful single lung transplantation on pulmonary haemodynamic variables and right ventricular function.

Design-Pulmonary haemodynamic variables and right ventricular function were measured at right heart catheterisation after single lung transplantation. The results were compared with the preoperative pulmonary haemodynamic variables measured at the time of assessment for transplantation.
\end{abstract}

Setting-A tertiary referral centre.

Patients-Five survivors of single lung transplantation performed for end stage lung disease.

Interventions-Cardiac catheterisation in all five patients at a mean of 18 months postoperatively. Preoperative catheter data were available for comparison in four. Right heart pressures and cardiac output were measured and right ventricular angiography was performed. Perfusion scans performed for clinical reasons were used to assess the percentage of cardiac output passing through each lung.

Main outcome measures-Right heart pressures, cardiac output, right ventricular function, percentage perfusion to lungs.

Results-After operation mean peak right ventricular pressure fell from 53 $\mathrm{mm} \mathrm{Hg}$ to $33 \mathrm{~mm} \mathrm{Hg}$, mean pulmonary artery pressure from $33 \mathrm{~mm} \mathrm{Hg}$ to 18 mm Hg, total pulmonary resistance from $11.2 \mathrm{U} \times \mathrm{m}^{2}$ to $5.8 \mathrm{U} \times \mathrm{m}^{2}$, and pulmonary arteriolar resistance from $8.9 \mathrm{U} \times \mathrm{m}^{2}$ to $3.6 \mathrm{U} \times \mathrm{m}^{2}$. Pulmonary artery wedge pressure and cardiac index were unchanged. Right ventricular function improved in all patients. The transplanted lung received most of the cardiac output.

Conclusion-In patients with moderate pulmonary hypertension and right ventricular dysfunction secondary to end stage fibrosing lung disease single lung transplantation was followed by an improvement in pulmonary haemodynamic variables and right ventricular function.

The development of single lung transplantation has given new hope of extended life expectancy and improved quality of life to patients with end stage fibrosing lung disease. patients with end stage fibrosing lung disease. Chronic pulmonary disorders are commonly associated with pulmonary hypertension, the severity of which influences outcome. ${ }^{1}$ Right ventricular dysfunction is invariably seen in patients with pulmonary hypertension and is associated with significant morbidity. We studied the effect of successful single lung transplantation on pulmonary haemodynamic variables and right ventricular function.

Patients and methods

Five recipients of single lung transplants (two men and three women; mean age 53 (range 45-61)) were studied by cardiac catheterisation at a mean of 18 months postoperatively (range 2-29). All were clinically well and transbronchial lung biopsy specimens showed no evidence of rejection at the time of investigation. They were on standard immunosuppressive therapy of prednisolone, azathioprine, and cyclosporin, and no patient was receiving diuretics or vasodilators. Preoperative catheterisation data were available for comparison in four patients. They had been obtained at a mean of four months before the operation (range 1-9). Histological examination of the removed lung showed that cryptogenic fibrosing alveolitis was present in four patients and eosinophilic granuloma in one. These patients were the first five recipients of single lung transplant to survive for more than a year at this unit. Twelve of the 20 patients we have operated upon are alive at mean follow up of 19 months (range 1-45) postoperatively.

Cardiac catheterisation was performed via the right femoral vein under local anaesthesia with patients breathing room air. Patients had not received premedication. Pressures were obtained from the right heart, cardiac outputs were measured by the thermodilution technique, and pulmonary resistances were calculated from these data. A right ventriculogram was recorded on biplane cinefilm for later analysis by two independent and blinded observers. Right ventricular function was graded according to the degree of chamber dilatation and systolic dysfunction. A score of 5 represented normal right ventricular function and a score of 1 represented considerable dilatation and severe hypokinesia. Data from those patients investigated before and after operation was analysed by Student's paired $t$ test. 
Individual catheter measurements before and after transplantation

\begin{tabular}{|c|c|c|c|c|c|c|c|c|c|c|c|c|c|c|}
\hline \multirow[b]{2}{*}{ Patient } & \multicolumn{2}{|c|}{$\begin{array}{l}P A s \\
(m m \mathrm{Hg})\end{array}$} & \multicolumn{2}{|c|}{$\begin{array}{l}P A d \\
(m m \mathrm{Hg})\end{array}$} & \multicolumn{2}{|c|}{$\begin{array}{l}P A m \\
(m m H g)\end{array}$} & \multicolumn{2}{|c|}{$\begin{array}{l}P A W \\
(m m \mathrm{Hg})\end{array}$} & \multicolumn{2}{|c|}{$\begin{array}{l}T P R \\
\left(\text { units } \times m^{2}\right)\end{array}$} & \multicolumn{2}{|c|}{$\begin{array}{l}P A R \\
\left(\text { units } \times m^{2}\right)\end{array}$} & \multicolumn{2}{|c|}{$\begin{array}{l}C I \\
l / \min / m^{2}\end{array}$} \\
\hline & Pre & Post & Pre & Post & Pre & Post & Pre & Post & Pre & Post & Pre & Post & Pre & Post \\
\hline $\begin{array}{l}1 \\
2 \\
3 \\
4 \\
5\end{array}$ & $\begin{array}{l}45 \\
43 \\
60 \\
58\end{array}$ & $\begin{array}{l}26 \\
32 \\
35 \\
30 \\
30\end{array}$ & $\begin{array}{l}15 \\
15 \\
30 \\
25\end{array}$ & $\begin{array}{r}10 \\
15 \\
10 \\
8 \\
10\end{array}$ & $\begin{array}{l}27 \\
27 \\
42 \\
37\end{array}$ & $\begin{array}{l}17 \\
21 \\
18 \\
15 \\
20\end{array}$ & $\begin{array}{l}7 \\
7 \\
8 \\
6\end{array}$ & $\begin{array}{l}8 \\
8 \\
7 \\
5 \\
7\end{array}$ & $\begin{array}{c}7.69 \\
9 \cdot 34 \\
16.6 \\
11.25\end{array}$ & $\begin{array}{l}4.75 \\
6.02 \\
7.09 \\
5.17 \\
7.91\end{array}$ & $\begin{array}{r}5 \cdot 70 \\
6.92 \\
13.44 \\
9.42\end{array}$ & $\begin{array}{l}2 \cdot 51 \\
3 \cdot 73 \\
3 \cdot 94 \\
4 \cdot 14 \\
2 \cdot 77\end{array}$ & $\begin{array}{l}3 \cdot 5 \\
2.9 \\
2.5 \\
3 \cdot 3\end{array}$ & $\begin{array}{l}3.6 \\
3.9 \\
2.5 \\
2.9 \\
2.5\end{array}$ \\
\hline
\end{tabular}

CI, cardiac index; PAd, pulmonary artery diastolic pressure; PAm, mean pulmonary artery pressure; PAR, pulmonary arteriolar resistance; PAs, pulmonary artery systolic pressure; PAW, mean pulmonary artery wedge pressure; TPR, total pulmonary resistance.

\section{Results}

The table and figures 1-3 show haemodynamic data (mean (SEM)) from individual patients before and after single lung transplantation. Peak right ventricular systolic pressure fell by $38 \%$, from 53 (5) $\mathrm{mm} \mathrm{Hg}$ to 33 (2) $\mathrm{mm} \mathrm{Hg}$ $(\mathrm{p}=0.0013)$ without a significant change in the diastolic pressure. Peak systolic pulmonary artery pressure fell by $40 \%$ from $52(4) \mathrm{mm} \mathrm{Hg}$ to $31(2) \mathrm{mm} \mathrm{Hg}(\mathrm{p}=0.012)$ and there was a fall of $46 \%$ in mean pulmonary artery pressure from 33 (4) $\mathrm{mm} \mathrm{Hg}$ to 18 (1) $\mathrm{mm} \mathrm{Hg}(\mathrm{p}=$ 0.039 ). Diastolic pulmonary artery pressure fell but this was not statistically significant. Total pulmonary resistance fell by $49 \%$ from 11.22 $(1.94) \mathrm{U} \times \mathrm{m}^{2}$ to $5.76(0.52) \mathrm{U} \times \mathrm{m}^{2}(\mathrm{p}=0.037)$, and pulmonary arteriolar resistance fell by $60 \%$ from $8.87(1.71) \mathrm{U} \times \mathrm{m}^{2}$ to $3.58(0.37)$ $\mathrm{U} \times \mathrm{m}^{2}(\mathrm{p}=0.038)$. There was no significant change in cardiac index or mean pulmonary artery wedge pressure. Body surface area rose by a mean of $8 \%$. The patient who was only catheterised postoperatively had normal right heart pressures and resistances (see table).

Figure 3 shows that there was an improvement in the grade of right ventricular function in all patients in whom angiograms were obtained before and after operation. The remaining patient had normal right ventricular function at catheterisation after transplantation. All patients had one preoperative ventilation and perfusion scan and regular postoperative ventilation and perfusion scans for routine clinical monitoring. From these the percentage of the cardiac output passing through each lung was calculated. Figure 4 shows the mean values. All patients had the left lung transplanted and the considerable switch of perfusion to this lung persisted at one year.

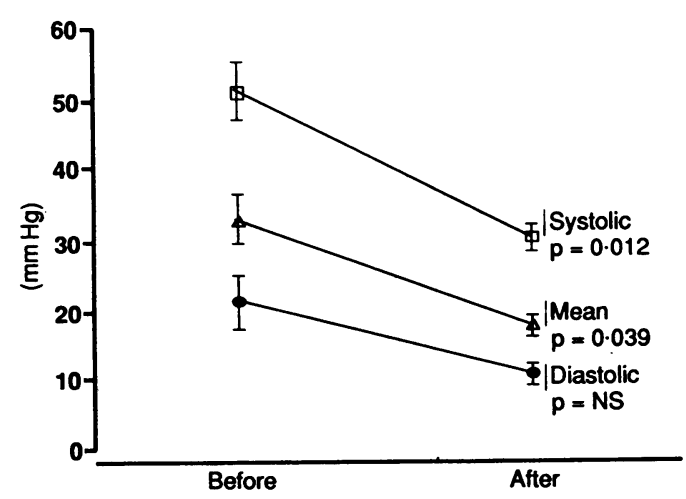

Figure 1 Pulmonary artery pressures before and after transplantation.

\section{Discussion}

Before the development of single lung transplantation in $1963^{2}$ and the first reports of success in $1983,{ }^{3}$ patients with end stage fibrosing lung disease had little prospect of survival, their final months being accompanied by significant morbidity. There were few treatments for the underlying lung condition if high dose prednisolone and cyclophosphamide failed. Any further treatment focused on the medical management of the secondary pulmonary hypertension. Domiciliary oxygen was the mainstay in hypoxaemic patients, but $\beta_{2}$ agonists, hydralazine, nitrates, calcium antagonists, and angiotensin converting enzyme (ACE) inhibitors have all been used with little benefit. ACE inhibitors have theoretical advantages in that they act directly on the pulmonary hypertension and also on the secondary fluid retention. Like all vasodilators, however, their effects are not confined to the pulmonary circulation and systemic vasodilatation is a major problem. ${ }^{4}$

The importance of pulmonary hypertension in single lung transplantation was unknown but the poor initial results with the procedure ${ }^{5}$ and the success of the Stanford Heart-Lung Transplant Programme ${ }^{6}$ meant that by 1986 , few successful single lung transplants had been performed. ${ }^{3}$ There are, however, several theoretical advantages to this approach for non-suppurative end stage lung disease. As in all patients in this series, the operation may be performed without cardiopulmonary bypass despite the presence of moderate pulmonary hypertension. It eliminates the problems of accelerated coronary artery disease in the trans-

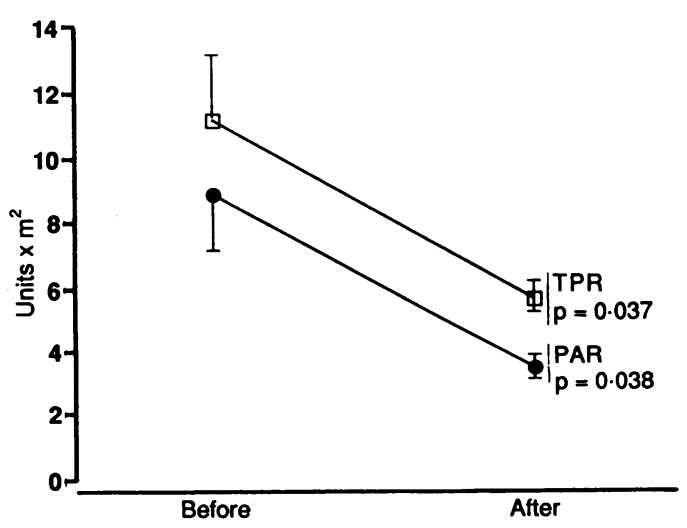

Figure 2 Total pulmonary (TPR) and pulmonary arteriolar $(P A R)$ resistances before and after transplantation. 
Figure 3 Right ventricular function at angiography before and after transplantation.

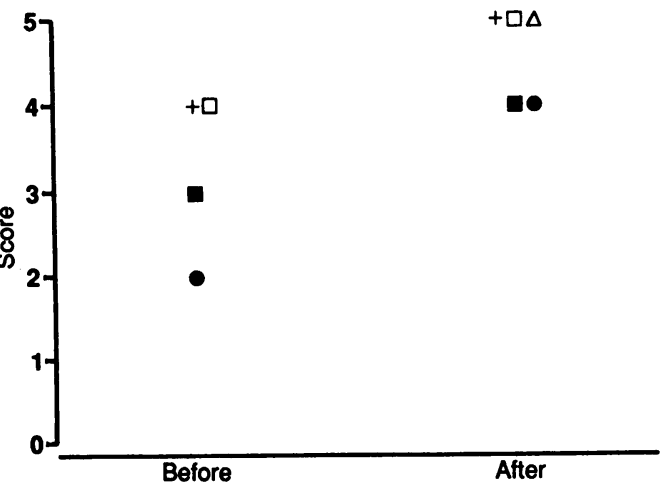

planted heart as well as freeing the heart and other donor lung for other recipients.

In dogs with induced pulmonary hypertension, it has been shown that single lung transplantation may be successfully performed. The transplanted lung is capable of taking most of the cardiac output ${ }^{7}$ with a considerable reduction in the pulmonary artery pressure. ${ }^{8}$ The single lung transplant programme at our institution was started shortly after the Toronto Lung Transplant Group reported two successful cases in $1986 .^{3}$ The results presented here confirm that the procedure can be performed successfully in patients with end stage fibrosing lung disease and define for the first time the haemodynamic response in human beings. The pulmonary vascular resistance falls as a result of the implantation of the healthy lung and tricular pressures fall. Eighty per cent of the cardiac output immediately passes into the donor organ and this situation seems to continue for at least one year. All our patients experienced a significant and long lasting improvement in their quality of life and exercise capabilities.

Many workers have confirmed that raised pulmonary artery pressures secondary to lung disorders are associated with a poor outcome. ${ }^{9}$ ${ }^{11}$ Weitzenblum et al showed that the survival rate in patients with pulmonary hypertension in chronic obstructive airways disease was $49 \%$ at four years and $29 \%$ at seven years. ${ }^{1}$ In the group without pulmonary hypertension, survival was $72 \%$ at four years and $56 \%$ at seven years. Pulmonary hypertension was defined as mild if the mean pulmonary artery pressure was between 20 and $30 \mathrm{~mm} \mathrm{Hg}$,

Figure 4 Percentage perfusion to each lung before and after left lung transplantation. consequently the pulmonary and right ven-

moderate if it was between 30 and $40 \mathrm{~mm} \mathrm{Hg}$, and severe if it exceeded $40 \mathrm{~mm} \mathrm{Hg}$. Various studies confirmed that the prognosis is especially poor if the mean pulmonary artery pressure is $>30 \mathrm{~mm} \mathrm{Hg},{ }^{12-14}$ as in our study population.

One of the major problems in the management of patients with secondary pulmonary hypertension is right ventricular dysfunction, which is invariably present and gives rise to significant morbidity. Exertional hypoxia worsens right ventricular function ${ }^{15}$ and this effect can occur in the absence of coronary artery disease. ${ }^{9}$ The right ventricle responds to alterations in preload with a minimal increase in stroke work. Unlike the left ventricle it deals poorly with increased afterload. ${ }^{16}$ Its function is notoriously difficult to assess by echocardiographic, ${ }^{15}{ }^{17}$ angiographic ${ }^{18}$ and radionuclide techniques. ${ }^{19}$ The awkward geometricvolumetric relations and the difficulty of obtaining satisfactory orthogonal views complicate the analysis of right ventricular function. The right ventricle contracts sequentially in a pattern similar to a peristaltic wave passing from the inflow to the outflow region after a systolic intracavitary chamber has been created. There are mechanical interactions with the left ventricle and problems of interpreting the paradoxical septal motion that is often seen. Recognising these difficulties, we elected to use a simple scoring system that would give an estimate of right ventricular function. There was an improvement after transplantation in all patients, and in some right ventricular function became normal. Even allowing for the problems of quantification of right ventricular function there is a strong inverse linear relation between systolic performance and afterload..$^{1820} 21$ That function improves after the removal of the high pulmonary resistance accords with the observations that there is good recovery after the removal of right ventricular banding in dogs. ${ }^{22}$

From these observations we conclude that single lung transplantation may successfully be carried out in the presence of moderate pulmonary hypertension and right ventricular impairment secondary to fibrosing lung disease. Pulmonary resistances and pressures are reduced without altering cardiac output or wedge pressure. Reducing the afterload allows right ventricular function to improve, sometimes to normal levels.

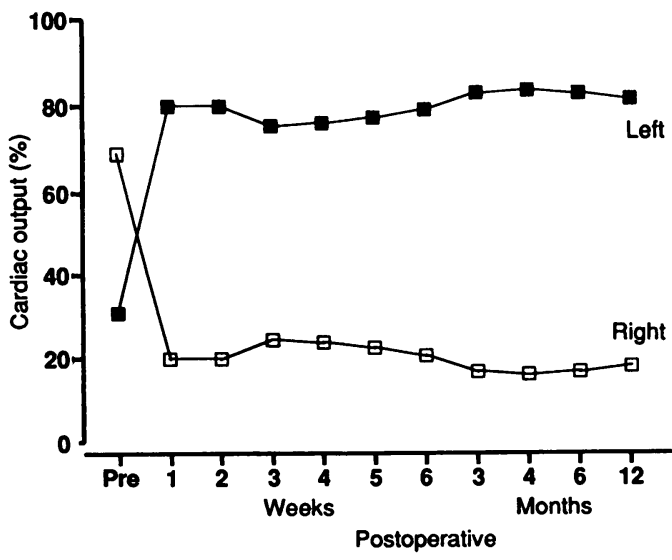

JCD is supported by a grant from the British Heart Foundation.

1 Weitzenblum E, Hirth C, Ducolone A, Mirhom R, Rasaholinjanahary J, Ehrhart M. Prognostic value of monary disease. Thorax 1981;36:752-8.

2 Hardy JD, Webb WR, Dalton ML, Walker GR. Lung homotransplantation in man: report of the initial case. JAMA 1963;186:1065-74. plantation for pulmonary fibrosis. $N$ Engl J Med 1986; 314:1140-5.

Veith FJ. 1986.314:1186-7.

6 Reitz BA, Wallwork JL, Hunt SA, et al. Heart-lung transpusano artery pressure in chronic obstructive pul-

3 Trans-

4 Peacoct A Pulmonary hypertension due to chronic hypoxia. 
plantation: successful therapy for patients with pulmonary vascular disease. $N$ Engl J Med 1982;306:557-64.

7 Eishi K, Takazawa A. Nagatsu M, et al. Pulmonary flowresistance relationships in allografts after single lung transplantation in dogs. J Thorac Cardiovasc Surg 1989; 97:24-9.

8 Fonkalsrud EW, Sarwat A-K, Higashijima I, Sanchez M. Chappell G. Lung allotransplantation in dogs with pulmonary hypertension. Arch Surg 1973;106:785-7.

9 Morrison DA. Pulmonary hypertension in chronic obstructive pulmonary disease: the right ventricular hypothesis. Chest 1987;92:387-8.

10 Burrows B, Kettel LS, Niden AH, Rabinowitz M, Diener CF. Patterns of cardiovascular dysfunction in chronic

11 Timms RM, Khaja FV, Williams GW, and the Nocturnal Oxygen Therapy Trial Group. Hemodynamic response to Oxygen Therapy Trial Group. Hemodynamic response to
oxygen therapy in chronic obstructive pulmonary disease. oxygen therapy in chronic obstructiv
Ann Intern Med 1985;102:29-36.

12 Ourednik A, Susa Z. How long does the pulmonary hypertension last in chronic obstructive broncho-pulmonary disease? Prog Respir Res 1975;9:24-8.

13 Massin N, Westphal JC, Schrijen F, Polu JM, Sadoul P. Valeur prognostique du bilan hemodynamique des bronchiteux chroniques. Bull Eur Physiopathol Respir 1979;15:821-37.

14 Bishop JM. Hypoxia and pulmonary hypertension in chronic bronchitis. Prog Respir Res 1975;9:10-6.
15 Mintz G, Panidis I. Assessment of right ventricular function. In: St John Sutton M, Oldershaw P, eds. Textbook of adult and pediatric echocardiography and Doppler. Boston: Blackwell Scientific Publications, 1989:155-68.

16 Niederman MS, Matthay RA. Cardiovascular function in secondary pulmonary hypertension. Heart Lung 1986, 15:341-51.

17 Feignbaum H. Echocardiography. 4th ed. Philadelphia: Lea and Febiger, 1986:127-87.

18 Redington AN, Rigby ML, Shinebourne EA, Oldershaw PJ. Changes in the pressure-volume relation of the right ventricle when its loading conditions are modified. $\mathrm{Br}$ Heart J 1990;63:45-9.

19 Morrison D, Goldman S, Wright AL, et al. The effect of pulmonary hypertension on systolic function of the right ventricle. Chest 1983;84:250-7.

20 Brent BN, Berger HJ, Matthay RA, Mahler D, Pytlik L, Zaret BL. Physiologic correlates of right ventricular ejection fraction in chronic obstructive pulmonary ejection fraction in chronic obstructive pulmonary disease: a combined radionuclide

21 Koor KS, Gandsman EJ, Winkler ML, Shulman RS, Bough EW. Hemodynamic correlates of right ventricular ejection fraction measured with gated radionuclide angiography. Am J Cardiol 1982;49:71-7.

22 Hsieh CM, Wang LS, Schaefers HJ, et al. Recovery of elevated atrial natriuretic peptide in pressure-overload right heart failure. $J$ Surg Res 1989;47:304-8.

\section{PLANTS IN CARDIOLOGY}

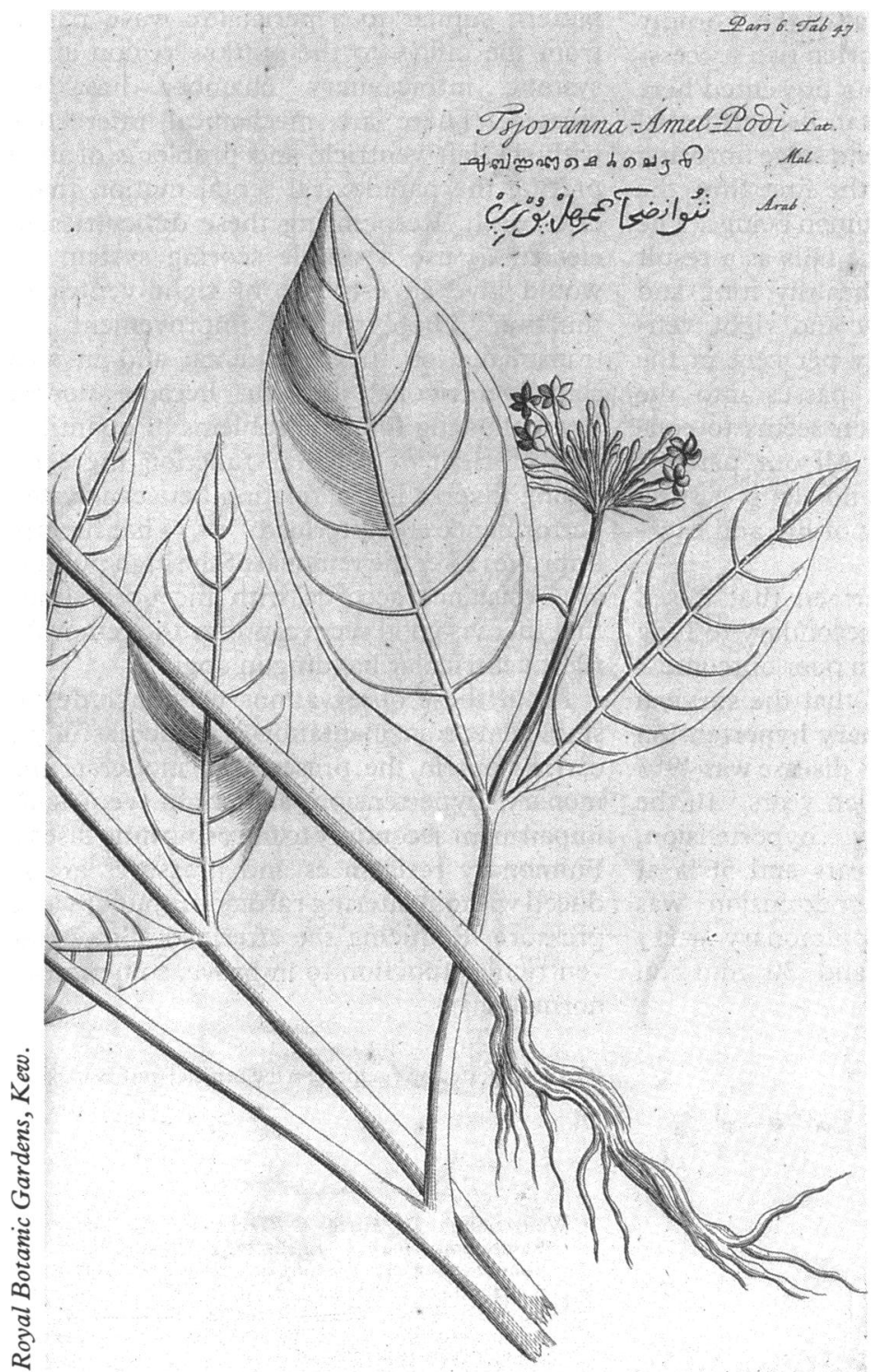

Rauvolfia serpentina Benth. ex Kurz. Rheede tot Draakestein, H A van. Hortus Indicus Malabaricus. Amsterdam: Johannes van Someren, 1686, volume 6, fig 47.

\section{Reserpine and ajmaline}

Rauvolfia serpentina (Apocynaceae) grows in India where it has been used in Hindu ayurvedic medicine since ancient times. The root resembles a snake and because of the Doctrine of Signatures it was given for snake bite. More importantly the root had a high reputation for calming the insane. In the 1930s psychiatric patients in Calcutta who were being treated with rauwolfia root were found to develop low blood pressure. Later the careful clinical trial of Vakil (British Heart Journal 1949;11:350-5) established its use in hypertension. Reserpine was the alkaloid that produced this effect and it was isolated in 1951. The term "tranquilliser" was coined in 1953 to describe its then unique calming and sedative effects. Mental depression limited its use in hypertension but another side effect, namely a parkinsonian syndrome, led to a remarkable therapeutic discovery. In 1959 Carlsson found that extrapyramidal symptoms in reserpine treated rabbits were caused by a deficiency of dopamine in the corpus striatum and that its precursor, dopa, reversed the symptoms. $\mathrm{He}$ pioneered levodopa treatment for Parkinson's disease.

There are many rauwolfia alkaloids, and in 1931 ajmaline was the first one to be found. It was named after Hakim Azmal Khan who founded the institute in Delhi where it was isolated, but its Class I antiarrhythmic action was not discovered until about 1965.

Rauvolfia (spelt with a v) is a genus of the tropical family Apocynaceae with 2100 species, mostly climbers, that are rich in secondary compounds. The vinca alkaloids are found in Catharanthus roseus, the Madagascar periwinkle. The cardiac glycosides strophanthus and ouabain occur in Strophanthus kombe and $S$ gratus.

A HOLLMAN 